\title{
Natural Killer Cell Mediated Defence Directed Selectively Against Target Cells Lacking MHC Class I Gene Products*
}

\author{
H.-G. Ljunggren, P. Höglund, C. Öhlén, and K. Kärre ${ }^{1}$
}

\section{Introduction}

Natural killer (NK) cells represent an important subset of lymphocytes. These cells fulfil crucial cytotoxic as well as regulatory functions of the immune system. Compromised NK cell activity has been found to be associated with the development of several diseases, including cancer, AIDS and virus infections. Intact NK cell activity appears to play an important role in health. More recent data suggests that NK cells may be involved in the pathogenisis of some human diseases and serve as an early predictor for susceptibility to disease [1]. In transplantation, NK cells participate in rejection of allogeneic bone marrow cells [2].

The molecular basis for the ability of NK cells to discriminate between normal and aberrant cells is not known in detail [3-5]. The aim of the present overview is to discuss studies of how target cell major histocompatibility complex (MHC) class I expression affects NK -target interactions and ultimately target susceptibility to NK cell mediated lysis.

The rationale for current studies is a hypothesis which has provided one test-

* This work has been supported by U.S. Public Health Service Grants 5 ROI CA25250-06 and 1 ROI CA-44882-01 awarded by the National Cancer Institute, The Swedish Cancer Society, The Swedish Society for Medicine, the Bristol Myers Company, and the Royal Swedish Academy of Sciences.

1 Dept. of Tumor Biology, Karolinska Institutet, Box 60400, S-10401 Stockholm, Sweden. able model for self - non-self discrimination by NK cells $[4,5]$. This hypothesis was originally based on (a) the patterns common to the various cytotoxic reactions attributed to NK cells and (b) a comparative analysis of the different strategies employed by vertebrates and invertebrates in order to distinguish between self and non-self. This hypothesis, presented as the "missing self" hypothesis [3], provided testable predictions for the investigation of the influence of the MHC class I gene products by NK cells. Briefly, it was suggested that NK cells could kill certain target cells because the latter express reduced levels of MHC class I molecules. This model underlies the work presented below. However, before going into the missing self hypothesis, present knowledge of NK cells and in particular their cytotoxic activity is briefly recapitulated.

\section{Natural Killer Cells}

The ability to kill certain tumour cell lines in vitro, without prior immunization or sensitization, was the first attribute of NK cells to be identified (reviewed in [6]). While this reaction was investigated in detail in the late 1970s several new insights as to their morphology, cell surface marker expression, tissue expression and action have become evident during the last 10 years (for reviews see e.g. [7-9]).

Morphologically, most NK cells are large granular lymphocytes (LGL). They are characterized by their intracytoplasmatic azurophilic granules and a high cytoplasm to nucleus ratio. In man, 
LGL comprise $2 \%-5 \%$ of peripheral blood lymphocytes. Early on, NK cells were found in the spleen peritoneal exudate and blood whereas they were scarcely found in lymph nodes, bone marrow, thoracic duct and the thymus. Later, NK cells were also isolated from the liver, tonsils, the epithelial lining of the upper respiratory tract and the lung interstitium [7-9].

NK cells commonly express certain cell surface markers, defined by monoclonal antibodies against $\mathrm{CD} 16$ (the Fc $\gamma$ III receptor for IgG) and NKH-1 in humans and NK-1.1/2.1 in mice [7-9]. Additional cell surface markers, some of which define subsets of NK cells, have recently been described [10]. NK cells are of bone marrow origin [6], but their exact lineage is uncertain. They share certain cell surface markers with $\mathrm{T}$ cells and also share some characteristics with monocytes. There is now a general belief that mature NK cells are distinct from $T$ lymphocytes [6-10].

The T-cell antigen receptor is not involved in NK cell recognition or cytotoxicity [7-9]. NK cells do not express CD3. There is no rearrangement of alpha-, beta-, gamma-, or delta-T cell receptor (TCR) genes and no synthesis of functional TCR messenger ribonucleic acid (mRNA) (even though nonfunctional beta and gamma TCR transcripts may be detected). However, CD3 positive (alpha-beta or gamma-delta) $\mathrm{T}$ cells may express, particularly upon activation, MHC nonrestricted cytolytic activity against target cells that are also sensitive to NK cells. According to a new definition proposed at the 5th International Natural Killer Cell Workshop (Hilton Head, S.C., 1988) these cells should not be termed NK cells but rather T cells displaying "NK-like" activity or "nonMHC-requiring" cytolysis [7, 8].

NK cells also respond to various lymphokines and interferons by elevated cytotoxic activity. They have been reported to produce different regulatory lymphokines themselves, e.g. IL-1, IL-2, IL-4, IL-5, interferons and colony- stimulating factors. Through such mediators (and maybe yet other unknown factors) NK cells are involved in regulation of haematopoesis and lymphocyte functions [7-9].

Natural resistance to infectious agents may be one of the more important functions for NK cells in vivo [11, 12]. Particularly during virus infections, high levels of IFN (primarily alpha or beta), are induced in lymphoid organs. Interferons activate NK cells to a higher level of cytotoxicity and stimulate their blastogenesis and proliferation in vivo. Biron et al. [12] recently described a patient with a complete and persistent absence of NK cells but otherwise normal immune functions. This patient first presented with an overwhelming varicella virus infection requiring treatment with acyclovir and later a life-threatening cytomegalovirus (CMV) infection.

\section{Graft Rejection \\ Mediated by NK Cells}

Soon after the discovery of NK cells it became clear that these cells could kill certain tumour cell lines in vitro in spite of the fact that they expressed no or only low amounts of MHC class I molecules $[13,14]$. This was a significant difference from cytotoxic $\mathrm{T}$ cells, which require the presence of MHC molecules to specifically kill target cells [15]. Further, NK cells were shown to be the effectors in rejection of small numbers of certain transplanted tumour cells $[6,16]$, in the prevention of metastasis [17] and in bone marrow graft rejection $[2,18]$. However, NK cells seem to have no or only little impact on established larger cancers. NK cells are not found within tumours; there is no clonal expansion, but rather a systemic suppression of NK activity [1].

A peculiar rejection mechanism, now attributed to NK cells, is the $\mathrm{F}_{1}$-hybrid resistance $[2,19,20]$. This phenomenon has been instrumental in recognizing the in vivo activity of NK cells and it is of particular importance for the following 
discussion. Hybrid resistance was first reported in 1958 when Snell [21] observed that homozygous lymphomas grew better in the strain of origin than in $F_{1}$ hybrids obtained by crossing this strain with another strain. This $F_{1}$ hybrid effect violated a principle in tissue transplantation. According to the genetic rules of histocompatibility, an $F_{1}$ hybrid should accept grafts from either of its parents. The most extensive genetic analysis of the $F_{1}$ hybrid effect was carried out by Cudkowicz [in 20] who studied rejection of normal bone marrow cells in $F_{1}$ hosts. They explained the phenomenon on the basis of a positive recognition of hypothetical recessive $\mathrm{Hh}$ genes expressed in the parental (and on the graft) but suppressed in the $F_{1}$ animal [20]. Snell [22] later offered an alternative interpretation in which $F_{1}$ hybrid resistance was seen as a result of a combined match and mismatch rather than a complete match between host effector cells and transplanted cells. This theory originated before NK cells were known to be the effector mechanism in hybrid resistance but nevertheless formed the basis for the missing self hypothesis (developed below), providing an alternative explanation to the Hh model. Critical experiments demonstrating that NK cells were the effector mechanism in $F_{1}$ hybrid resistance were published in 1977 by Kiessling et al. [2]. Before that, Kiessling et al. [23] and Petranyi et al. [24] had reported a correlation between NK activity in vitro and tumour resistance in vivo among $F_{1}$ hybrids. Klein et al. [25] extended these conclusions and mapped $F_{1}$ hybrid resistance to the H-2 gene complex in several different tumour combinations. Carlson et al. [26] observed a rapid elimination of intravenously injected leukaemia cells whenever these were "mismatched", i.e. H-2K or D products were not present in relation to the host. This elimination occurred in nude mice but not in NK depleted mice.

Allogeneic lymphocyte cytotoxicity is a term used for the rapid destruction of intravenously injected allogeneic lym- phocytes by unsensitized hosts. Allogeneic lymphocyte cytotoxicity has been reported in several mammalian species and it has been studied most extensively in rats [27]. It is mediated by NK cells and is in certain aspects related to $F_{1}$ hybrid resistance.

\section{Strategies for Self-Non-self Discrimination: the Missing Self Hypothesis}

Multicellular organisms need defence systems against destruction of their tissues by foreign invaders as well as against altered endogenous cells. A prerequisite for such a defence reaction is recognition of the potential threat. An organism should be able to discriminate between "self", i.e. everything constituting an integral part of a given individual, and the rest. This recognition could, in theory, be positive or negative [28]. In positive recognition, the organism actively recognizes "non-self" and reacts against it. In negative recognition, there is an active recognition of self and the reaction is triggered only as a consequence of the failure to recognize self. It is well known that higher vertebrates have evolved defence systems based on positive recognition. This is mediated by $T$ and $\mathrm{B}$ cells which have clonally distributed receptors generated partly by a random process. The receptor repertoire is then somatically selected for the ability to positively identify "foreignness" either directly (B cells) or in the context of molecules of the MHC (T cells).

The missing self hypothesis is based on the second, negative type of recognition. It was suggested that NK cells kill certain targets because they fail to express adequate levels of self MHC class I gene products [3-5] (Table 1). This hypothesis originated from the observations that NK cells mediate rejection of allogeneic lymphoma and bone marrow grafts $(\mathrm{H}-$ $2^{a / a}$ rejects $\mathrm{H}-2^{\mathrm{b} / \mathrm{b}}$ ) and also, in contrast to cytotoxic $\mathrm{T}$ lymphocyte (CTL), $\mathrm{F}_{1^{-}}$hybrid anti-parental resistance. In the 
Table 1. Triggering signals for $T$ cells and NK cells

\begin{tabular}{|c|c|c|}
\hline Cell type & $\begin{array}{l}\text { Strategy for self - non-self } \\
\text { recognition }\end{array}$ & Signal \\
\hline $\mathrm{T}$ cell & "Positive" recognition & $\begin{array}{l}\text { Presence of a foreign antigen } \\
\text { presented in the context of } \\
\text { class I molecules of the MHC } \\
\text { (triggering signal) }\end{array}$ \\
\hline NK cell & "Negative" recognition & $\begin{array}{l}\text { Presence of "self" class } \\
\text { I molecules of the MHC } \\
\text { (inhibitory signal) }{ }^{\mathrm{a}}\end{array}$ \\
\hline
\end{tabular}

a Note that this does not exclude other (MHC class I independent) triggering signals as well (see [3]).

allogeneic as well as in the $\mathrm{F}_{1}$ hybrid antiparental situation, the graft "fails" to express at least one $\mathrm{H}-2$ class I allele of the host. This failure to express a complete set of self MHC class I molecule by the target was postulated to be sufficient to cause elimination by NK cells [4, 5].

Transposed to an autologous situation, the hypothesis predicted that absence or reduced expression of self $\mathrm{MHC}$ class I products (whether caused by mutation, transformation, arrest in differentiation or virus infection) could be sufficient to make a cell recognized and rejected by NK cells $[4,5]$. Conversely, an induction of self $\mathrm{MHC}$ class I molecules on such a target cell should be sufficient to prevent rejection mediated by NK cells. These predictions have been tested in vivo and the results will briefly be discussed below.

\section{Immunological Defence Against H-2 Class I Deficient Cells in Vivo}

In order to test the missing self hypothesis we chose to work with the wellcharacterized $\mathrm{C} 57 \mathrm{Bl} / 6$ derived RBL-5 and EL-4 murine lymphoma cell lines (H$2^{\mathrm{b}}$ haplotype). These lymphomas express high levels of $\mathrm{H}-2$ and are highly malignant in the syngeneic host. Our experimental approach was to test the prediction that selection for loss of $\mathrm{H}-2$ class I expression should be accompanied by an increased sensitivity to natural resistance in vivo and in vitro $[4,5]$.
As a starting point, $\mathrm{H}-2$ deficient variant lines were selected from the RBL-5 and EL-4 lymphomas [5, 29]. Titrated doses of wild type and variant cells were inoculated either subcutaneously [5, 29], intravenously or intraperitoneally [30] in small groups of mice, age matched and usually littermates, in several independent experiments and tumorigeneicity was scored. This strategy minimized the risk that random fluctuations in the quality of the respective cell suspensions would be responsible for differences in the ability to form tumours.

In line with the prediction of the hypothesis, the $\mathrm{H}-2$ class I deficient RBL-5 and EL-4 variants were rejected in syngeneic C $57 \mathrm{BL} / 6$ mice after a small tumour inoculum $\left(10^{3}\right.$ to $10^{5}$ cells), whereas mutagenized but non-selected, $\mathrm{H}-2$ positive, wild type lines were highly tumorigenic in the corresponding doses [5, 29]. The $\mathrm{H}-2$ deficient cells required a $10^{3}$ to $10^{4}$-fold higher dose than the $\mathrm{H}-2$ positive cells to induce more than $50 \%$ tumour take irrespective if the cells were inoculated subcutaneously, intravenously or intraperitoneally $[5,29,30]$.

The rejection of the $\mathrm{H}-2$ deficient lines showed several characteristics of an NK mediated response, including thymus independence and no requirement for preimmunization [5, 29]. The resistance was weakened (but not totally abrogated) by $400 \mathrm{rad}$ irradiation [29], and it was sufficient to remove asialo-GM $\mathrm{GM}_{1}$ or $\mathrm{NK} 1.1$ positive cells (NK cells) from the animal 
to abrogate the rejection ([29], unpublished results). Experiments comparing the distribution and survival of isotope prelabeled variant and wild type cells indicated that a rapid elimination of the former took place within $24 \mathrm{~h}$ after intravenous injection. These differences in rapid elimination of tumour cells were abolished in NK depleted mice [29]. The above mentioned pattern was observed in all organs studied with one exception the brain (discussed in detail in [30-32]).

One possible explanation for the differential rejection patterns of the $\mathrm{H}-2$ positive and $\mathrm{H}-2$ deficient lymphoma cell lines in the syngeneic B6 mice was a difference in an afferent arm of a $\mathrm{NK}$ dependent host response [33]. In this scenario the $\mathrm{H}-2$ deficient cells would recruit NK effector cells which would kill $\mathrm{H}-2$ positive and deficient cells equally well without discriminating between them. However, the differential rejection pattern remained when $\mathrm{H}-2$ positive and deficient cells were inoculated into the same animals, whether in different flanks [29] or mixed in the same inoculum [33]. $\mathrm{H}-2$ deficient cells were selectively eliminated even when they were present in a 10-fold excess compared to $\mathrm{H}-2$ positive cells in the same inoculum [33]. These results suggested that the NK dependent response against $\mathrm{H}-2$ deficient cells was selective in an efferent (effector) arm of the response [33].

In recent experiments we have demonstrated that it is possible to restore the tumorigenicity of $\beta 2$-microglobulin $(\beta 2 \mathrm{~m})$ negative EL-4 cell lines by transfection of $\beta 2 \mathrm{~m}$ (R. Glas et al., to be published). This indicates that $\beta 2 \mathrm{~m}$ may act as a tumour growth promoting gene when the host defence is dominated by NK cells.

The "missing self" hypothesis predicted that it should be possible to obtain NK mediated rejection of a $\mathrm{H}-2$ positive target provided that the host carried one (or several) extra MHC class I allele(s) in relation to the target. $F_{1}$ hybrid resistance and allogeneic lymphocyte rejection were postulated to be examples of this $[4,5]$. To directly test this concept, still within the RBL-5 model, we used the transgenic strain D8 generated by Bieberich et al. [34]. The D 8 strain was produced by introducing an $8.0-\mathrm{kb}$ genomic fragment containing the $\mathrm{H}-2 \mathrm{D}^{\mathrm{d}}$ gene and $2.5 \mathrm{~Kb} 5^{\prime}$ and $2.0 \mathrm{~Kb} 3^{\prime}$ flanking sequences into B6 zygotes. The transgene product was expressed in different tissues in the same way as the endogenous $\mathrm{H}-2^{b}$ haplotype products, without alterations in the expression of the latter. Tumour growth was followed after subcutaneous inoculation of graded doses of RBL-5 lymphoma cells in D8 and B6 control mice [35]. The D8 strain was more resistant to subcutaneous challenge of "previously syngeneic" RBL-5 lymphoma cells than B 6 controls. The direct role of the H-2D ${ }^{d}$ gene in this resistance was investigated by the use of $(\mathrm{D} 8 \mathrm{XB} 6) \mathrm{F}_{1}$ crosses and (D8XB6)XB6 backcrosses. The latter showed cosegregation with regard to the $\mathrm{D}^{\mathrm{d}}$ expression and lymphoma resistance, both of which were inherited in a pattern consistent with control by a single dominant gene [35]. The resistance to RBL-5 (or other B6 derived lymphomas) in the D 8 strain could be abrogated by pretreating mice with anti-asialo $\mathrm{GM}_{1}$ antiserum or anti-NK $1.1 \mathrm{mAb}$, indicating that NK cells were necessary for the rejection [35] Subsequent studies have shown that the elimination of RBL-5 in D8 is a rapid event taking place within $24 \mathrm{~h}$ (P. Höglund et al., J Exp Med, in press). In thus entirely resembles the elimination of RBL-5 $\mathrm{H}-2$ deficient variant cells in B6 mice. A similar pattern was seen when the D8 strain was grafted with B 6 bone marrow. The $\mathrm{D} 8$ recipients had acquired an ability to reject bone marrow from $\mathrm{C} 57 \mathrm{BL} / 6$ donors but not from D8 donors and this rejection was dependent on the presence of NK cells in the host [18].

Recessive $\mathrm{Hh}$ antigens have been mapped to the $D$ region of the $\mathrm{H}-2$ complex, although rejection did not require expression of the dominant $\mathrm{D}$ locus product of the graft (reviewed in [20]). Our data do not address the role of putative $\mathrm{Hh}$ antigens at the tumour/graft 
level. However, no transcripts have been detected from the flanking sequences of the $D^{d}$ gene carried by the construct (G. Jay, unpublished observations). It is therefore concluded that the $\mathrm{D}^{\mathrm{d}}$ gene itself is responsible for the resistance at the level of the host. These results are consistent with the predictions of the missing self hypothesis [3-5].

In conclusion, the results are in line with an NK cell mediated rejection of small tumour or bone marrow grafts providing that the graft lacks (or expresses greatly reduced levels) of at least one MHC class I allele of the host.

\section{MHC Expression and Tumorigenicity - a Re-evaluation}

The results obtained with the $\mathrm{H}-2$ deficient lymphoma grafts in vivo predicted that if the critical immunological hosttumour interaction is dominated by NK cells rather than $T$ cells in a given system, up-regulation of MHC class I expression would make tumour cells more malignant because they would survive interactions with NK effectors.

This has been observed in studies with different sublines of the mouse B16 melanoma, pioneered by Taniguchi et al. [37]. $\mathrm{H}-2$ positive melanoma cells gave rise to a high number of metastatic lung colonies, whereas the $\mathrm{H}-2$ low or deficient melanoma cells gave no or only few colonies after intravenous inoculation [37]. Sub- sequent studies showed that the nonmetastatic H-2 deficient sublines acquired metastatic capacity if they were pretreated with inteferon (IFN), known to enhance H-2 class I expression, or if the mice were pretreated with anti-asialo GM1 serum, known to deplete NK cells [38].

In contrast to the result reviewed above, there are several reports in which decreased expression of MHC class I molecules are associated with enhanced tumour growth (reviewed in $[39,40])$. The apparently conflicting results may depend on the antigenicity of the tumour and/or the experimental protocol used [3, 41]. This can be illustrated with the RBL5 lymphoma, for which opposite results with regard to tumorigenicity were obtained when $\mathrm{H}-2$ positive and deficient variants of this tumour were compared in two different experimental situations (Table 2):

1) A small subcutaneous inoculum in untreated mice led to growth of $\mathrm{H}-2$ positive cells and NK dependent elimination of $\mathrm{H}-2$ deficient cells, and

2) A large subcutaneous inoculum in preimmunized mice resulted in $\mathrm{T}$ cell dependent elimination of $\mathrm{H}-2$ positive cells and growth of $\mathrm{H}-2$ deficient cells which overrode the limited nonadaptive NK response.

Had the tumours only been tested under the latter conditions, we would erroneously have concluded that loss of class I

Table 2. Influence of experimental protocol on NK versus $\mathrm{T}$ cell mediated rejection of RBL-5 $\mathrm{H}-2$ positive and $\mathrm{H}-2$ deficient sublines in $\mathrm{B} 6$ mice $^{\mathrm{a}}$

\begin{tabular}{llll}
\hline $\begin{array}{l}\text { RBL-5 } \\
\text { tumour dose }\end{array}$ & $\begin{array}{l}\text { H-2 } \\
\text { expression }\end{array}$ & $\begin{array}{l}\text { Pretreatment } \\
\text { of the host }\end{array}$ & $\begin{array}{l}\text { Progressive } \\
\text { tumour growth }\end{array}$ \\
\hline Low & High & - & Yes \\
Low & Low & - & No \\
High & High & - & Yes \\
Hig & Low & - & Yes \\
High & High & Preimmunization & b \\
High & Low & Preimmunization & Yes \\
\hline
\end{tabular}

a Data based on $[5,29,33]$ and H. G. Ljunggren et al. (unpublished observations).

b Preimmunized with RBL-5 (resembling grafting with a highly immunogenic tumour). 
molecules is only associated with enhanced tumorigenicity of the tumour.

Thus, there is no obligatory association between reduced $\mathrm{H}-2$ class I expression and increased malignancy. The effect of MHC class I expression on rejection or escape from immunological rejection will depend on the dominant host-tumour interaction. Such interactions may vary in different phases of tumour progression and under different experimental conditions $[3,41]$.

Tests for the effect of MHC modulation on tumour growth or immunotherapy therefore require careful experimental design to cover the action of different effector mechanisms in vivo. Since $\mathrm{T}$ cell responses, once elicited, would play a dominant role in the final outcome of tumour growth, the effect of $\mathrm{H}-2$ changes on the NK defence could rather easily be missed in studies with relatively large tumour grafts and immunogenic tumours. This possibility can be controlled in any system, by using small grafts or short-term assays where rapid rejection of grafted cells is monitored, either in conventional transplantation assays or in tests of the survival of radiolabelled cells [29]. Additional controls can be obtained by the use of mice with either genetically inherited immunodeficiencies (e.g. nude mice or SCID mice) or mice where different subsets of the host immune defence experimentally has been depleted (e.g. irradiated, thymectomized, anti-NK 1.1 treated, anti-asialo $\mathrm{GM}_{1}$ treated, antiL 3 T 4 treated or anti-Ly 2 treated mice).

\section{NK Sensitivity of MHC Class I Deficient Cells In Vitro}

A detailed review of the in vitro NK sensitivity of MHC class I deficient cells has recently been published [3]. A brief summary is given below.

The MHC class I deficient RBL-5 and EL-4 murine lymphoma cell lines, used in the in vivo studies described above, showed enhanced NK sensitivity in vitro compared to their wild type counterparts $[3,5,33]$. The association between high NK sensitivity and reduced MHC class I expression in murine models is not confined to lymphoma or melanoma variants derived by mutagenization and selection in vitro. Fibrosarcoma clones with constitutively low $\mathrm{H}-2$ expression derived by cloning without selection were sensitive to NK mediated lysis, while clones (from the same primary tumour) with high levels of $\mathrm{H}-2$ expression were resistant [42].

Increased $\mathrm{NK}$ sensitivity of human $\mathrm{MHC}$ class I deficient variants was first reported by Harel-Bellan et al. [43] and Storkus et al. [44]. They analysed T-LCL, B-LCL and B and T cell hybrid cell lines. The latter group analysed three different sets of cloned cell lines with corresponding variants that differed in their relative HLA class I expression. While sensitivity correlated with reduced class I expression it did not correlate with class II expression or transferring receptor expression [44]. In one of two more recent confirmatory studies on NK sensitivity of HLA deficient variants $[45,46]$, IL-2 activated effectors gave the same MHC class I related pattern as fresh NK cells while allospecific CTL lines showed an opposite pattern [45]. The latter study also showed that an intermediate HLA class I expressor (Haplotype loss) variant was moderately NK sensitive (compare to the relatively resistant wild type line), whereas a weak HLA class I expressor (with an additional down regulation of the remaining haplotype) was highly sensitive [45].

Enhanced NK sensitivity of murine and human $\mathrm{MHC}$ class I deficient variant lines does not correlate with a single molecular defect (see [47]). Rather, it appears that increased $\mathrm{NK}$ sensitivity can result from different defects in the MHC class I biosynthesis with the common denominator that cell surface expression of class I molecules was impaired.

In order to directly study whether MHC class I gene products can affect NK sensitivity it is essential to study cell lines 
transfected with different genes with the purpose to specifically restore the HLA/H-2 class I expression. The first studies in this direction did not support a role for MHC class I gene products. The murine line 1 carcinoma express little if any $\mathrm{H}-2 \mathrm{D}^{\mathbf{d}}$ in vitro [48]. Transfection of $\mathrm{H}-2 \mathrm{D}^{\mathrm{p}}$ into line 1 led to a constitutive and dimethyl sulphoxide (DMSO) inducible expression of $\mathrm{H}-2 \mathrm{D}^{p}$ but this expression had no influence on NK sensitivity. Transfection of $\mathrm{H}-2 \mathrm{~K}^{\mathrm{b}}$ into a hepatoma gave a less conclusive result (reduced NK sensitivity in 4/9 experiments, no effect in $5 / 9$ experiments) [49]. The authors further concluded that there was no difference in tumour formation between wild type and transfected cells, and thus that $\mathrm{H}-2 \mathrm{~K}^{\mathrm{b}}$ did not affect either NK susceptibility or tumorigenicity. The latter conclusion was based on an i.m. inoculation of $10^{7}$ cells [49], as opposed to low dose inocula used to study rejection of $\mathrm{H}-2$ deficient cells as reviewed in the present overview (Table 2).

However, when Quillet et al. [50] transfected the human $\beta 2 \mathrm{~m}$ gene into the $\beta 2 \mathrm{~m}$ negative human Burkitt lymphoma cell line Daudi, this led to the establishment of a line permanently expressing HLAA 10, -A 11 and B-17 class I molecules. This transfected line showed a reduced sensitivity to both NK and lymphokine activated killer (LAK) cell lysis as compared to the HLA class I negative wild type cell line [50]. Transfection of the human HLA class I deficient lymphoblastoid B cell line C1R with HLA-A3, HLA-B 7 and HLA-Bw58 also led to a reduction in NK sensitivity [51]. Although there was no significant variation among the HLA-A 3, -A 7 and -Bw58 alleles, HLA-A2 appeared unable to protect from NK cell lysis [51]. Comparison of amino acid sequence suggests a restricted number of residues which may be relevant to the protective effect. The protection did not extend to $\mathrm{H}-2 \mathrm{D}^{\mathrm{p}}$ or $\mathrm{K}^{\mathbf{b}}$ transfected C1R cells, nor was it seen when IL-2 stimulated NK effector cells were used [51]. Another B cell lymphoblastoid cell line, 0.221 , with a selective loss of HLA class I expression was transfected with HLA-A1, HLA-A2, HLAB8, HLA-B 5 or an HLA-C gene [46]. Expression of $\mathrm{MHC}$ class I genes reduced NK cell sensitivity, with a general tendency for HLA-B genes to have the most prominent effect.

Transfection of human melanoma cells with c-myc is associated with a specific down regulation of class $I$ expression which is most prominent for the B locus products [52]. This is associated with an increased sensitivity to NK cell lysis [53]. Interestingly, this increased NK sensitivity can be overcome by super-transfection of HLA-B7 and B27 genes to the melanoma cells which restores the original NK resistant phenotype (P. Schrier, personal communication). The increased NK sensitivity of melanomas with a c$m y c$ induced HLA-B suppression as well as some of the above-mentioned transfection studies suggested that selective down regulation of certain allelic or locus specific products (and not necessarily all class I molecules) might be sufficient to induce NK sensitivity. This is interesting in relation to two papers describing the failure to induce a significant NK resistance upon transfection with HLA-A2 $[54,55]$.

There are now two murine analogues to the rescue of HLA in $\beta 2 \mathrm{~m}$ transfected Daudi cells. Sturmhöfel and Hämmerling [56] selected an $\mathrm{H}-2$ class I deficient line (S3) from the murine EL-4 cell line. This variant was found to have a defect in $\beta 2 \mathrm{~m}$ expression and was highly sensitive to NK cell lysis. Transfection of the S3 line with the $\beta 2 \mathrm{~m}$ clone restored cell surface $\mathrm{H}-2$ expression and resulted in a considerable decrease in NK sensitivity. Transfection of class II genes had no effect. Blocking of class I molecules with Fab fragments against class I molecules increased NK sensitivity of EL-4 to the level of the S3 variant [56]. The second example is the transfection of the $\beta 2 \mathrm{~m}$ deficient YAC-1 variant A.H-2- with $\beta 2 \mathrm{~m}$. This restored the YAC-1 phenotype with respect to inducible class I expression and a concomitant protection 
from NK cell lysis after treatment with IFN-gamma [57]. The YAC-1 lymphoma has also recently been transfected with $\mathrm{H}$ $2 \mathrm{~K}^{\mathrm{b}}$ under control of the human metallothionein IIA promoter. These transfected $\mathrm{H}-2 \mathrm{~K}^{\mathbf{b}}$ positive sublines showed a reduced sensitivity to murine NK cell lysis [58].

At this stage it can be concluded that expression of certain MHC class I molecules can reduce NK sensitivity in several targets. Different molecular models for how MHC class I molecules can protect certain target cells as well as interpretations of the systems where MHC class I genes do not have this effect on NK sensitivity has recently been discussed (see [3]).

\section{General Conclusions and Future Prospects}

In the present overview we have discussed an NK cell defence against MHC class I deficient cells. The data in support of this concept were obtained with murine MHC class I deficient variant cell lines and their corresponding wild type cell lines in in vivo and in vitro studies. Using $\mathrm{MHC}$ class I transgenic mice, we have demonstrated that a deficiency of a single host MHC class I allelic product on a tumour cell graft is sufficient to cause rejection. $\beta 2 \mathrm{~m}$, one of the three subunits of an MHC class I molecule $[59,60]$, is the first identified molecule that contributes to the IFN-gamma mediated protection from NK cell lysis [57]. This was suggested, although formally not proven, to be mediated through the increased cell surface expression of class I molecules of the MHC. The general concept of a surveillance system geared to detect "missing self" explains some conflicting results regarding the relationship between MHC class I expression, tumorigenicity and metastasis (see [3]). The concept can also explain $\mathrm{F}_{1}$-hybrid resistance and rapid elimination of allogeneic lymphocytes by NK cells. Rapid elimination of allogeneic lymphocytes, transferred during for example pregnancy or sexual contacts where the transferred cells may cause tissue damage by graft versus host or by transmitting infectious agents such as HIV, may be an important defence action by NK cells. From a more general immunological point of view the present results have challenged the notion that discrimination between self and non-self is the only strategy for immunological elimination of aberrant cells in mammals [3-5]. In relation to clinical bone marrow transplantation, the present defence system may be taken into consideration in discussions of host versus graft reactions [18].

The analysis of models where MHC class I molecules clearly do affect NK sensitivity must now focus on detailed molecular events. Experimental strategies for this analysis has recently been described [3]. The mechanism by which an NK cell recognizes a target cell, deficient in self MHC class I expression is unknown. A detailed analysis as to which parts of the MHC class I molecule contribute to the inhibit ion of NK cell lysis must be undertaken. Such an analysis may lead to insights into the recognition event. Other studies must focus on defining receptor-like structures on NK cells. In an "effector inhibition" model [3] certain specific questions could be asked. Does one of the NK receptors resemble a $\mathrm{T}$ cell receptor due to a possible $\mathrm{MHC}$ class I binding ability? Is such a receptor primed to recognize only presence of self MHC class I molecules, and does it trigger the lytic machinery if appropriate class I molecules are not recognized? It would also be of interest to know when during ontogeny NK cells learn to discriminate between self and non-self. Do NK cells themselves need to express self MHC class I in order to recognize absence of self $\mathrm{MHC}$ class I? Are quantitative levels of MHC class I on the target monitored relative to the MHC class I expression on the NK cell itself? The ultimate model for such and related studies may be $\beta 2 \mathrm{~m}$ deficient mice as recently described in the literature [61, 62]. 


\section{References}

1. Whiteside TL, Herberman RB (1989) The role of natural killer cells in human disease. Clin Immunol Immunopathol 53:123

2. Kiessling R, Hochman PS, Haller $O$, Shearer GM, Wigzell H, Cudkowicz G (1977) Evidence for a similar or common mechanism for natural killer cell activity and resistance to hemopoetic grafts. Eur J Immunol 7:655-663

3. Ljunggren HG, Kärre K (1990) In search of the missing self: MHC molecules and NK cell recognition. Immunol Today $11: 237-244$

4. Kärre K (1985) Role of target histocompatibility antigens in regulation of natural killer activity: a reevaluation and a hypothesis. In: Herberman RB, Callewaert D (eds) Mechanisms of cytotoxicity by NK cells. Academic, New York, pp 81-91

5. Kärre K, Ljunggren HG, Piontek G, Kiessling $R$ (1986) Selective rejection of $\mathrm{H}-2$ deficient lymphoma variants suggests alternative immune defence strategy. Nature 319:675-678

6. Kiessling R, Wigzell $\mathrm{H}$ (1979) An analysis of murine NK cells as to structure, function and biological relevance. Immunol Rev 44:165-208

7. Hercend T, Schmidt RE (1988) Characteristics and uses of natural killer cells. Immunol Today 9:291-293

8. Ades EW, Lopez C (eds) (1989) Natural killer cells and host defence. Karger, Basel

9. Trinchieri G (1989) Biology of natural killer cells. Adv Immunol 47:187-375

10. Sentman CL, Hacket J, Kumar V, Bennet $M$ (1989) Identification of a subset of murine natural killer cells that mediates rejection of $\mathrm{Hh}-1 \mathrm{~d}$ but not $\mathrm{Hh}-1 \mathrm{~b}$ bone marrow grafts. J Exp Med 170:191-202

11. Welsh RM, Fitzgerald-Bocarsly P (1989) Anti microbial defence by NK cells: Chairmen's summary. In: Ades EW, Lopez C (eds) Natural killer cells and host defence. Karger, Basel, pp 105-107

12. Biron CA, Byron KS, Sullivan JL (1989) Severe herpesvirus infection in an adolescent without natural killer cells. N Engl J Med 320:1731-1735

13. Trinchieri G, Santoli D (1978) Anti-viral activity induced by culturing lymphocytes with tumor derived or virus-transformed cells. J Exp Med 147:1314-1333
14. Stern P, Gidlund M, Örn A, Wigzell H (1980) Natural killer cells mediate lysis of embyonal carcinoma cells lacking MHC. Nature 285:341-342

15. Yedell JW, Bennik JR (1990) The binary logic of antigen processing and presentation to $\mathrm{T}$ cells. Cell 62:203-206

16. Kärre K, Klein GO, Kiessling R, Klein G, Roder JC (1980) Low natural in vivo resistance to syngeneic leukemias in natural killer-deficient mice. Nature 284:624-626

17. Hanna N, Fidler IJ (1981) Relationship between metastatic potential and resistance to natural killer cell mediated cytotoxicity in three main tumor systems. INCI 66:1183-1190

18. Öhlén $C$, Kling $G$, Höglund $P$, Hansson M, Scangos G, Bieberich C, Jay G, Kärre K (1989) Prevention of allogeneic bone marrow graft rejection by $\mathrm{H}-2$ transgene in donor mice. Science 246:666-668

19. Cudkowicz G, Bennet M (1971) Peculiar immunobiology of bone marrow allografts. II. Rejection of parental grafts by resistant F1 hybrid mice. J Exp Med 134:1513-1528

20. Bennet $M$ (1987) Biology and genetics of hybrid resistance. Adv Immunol 41: $333-445$

21. Snell GD (1958) Histocompatibility genes of the mouse. II. Production and analysis of isogenic-resistant lines. I Natl Cancer Inst 21:843-877

22. Snell GD (1976) Recognition structures determined by the H-2 complex. Transplant Proc 8:147-156

23. Kiessling R, Petranyi G, Klein G, Wigzell $H$ (1976) Non T cell resistance against a mouse Moloney lymphoma. Int J Cancer 17:275-281

24. Petranyi G, Kiessling R, Povey S, Klein G, Hertzenberg L, Wigzell H (1976) The genetic control of natural killer cell activity and its association with in vivo resistance against a Moloney isograft. Immunogenetics 3:15-28

25. Klein GO, Klein G, Kiessling R, Kärre K (1978) H-2 associated control of natural cytotoxcity and hybrid resistance against RBL-5. Immunogenetics 6:561-569

26. Carlson GA, Melnychuk D, Meeker MJ (1980) H-2 associated resistance to leukemia transplantation: natural killing in vivo. Int J Cancer 25:83-89 
27. Heslop BF, Mcneilage LJ (1989) The F1 hybrid effect in allogeneic lymphocyte cytotoxicity. Transplantation 48:634-639

28. Klein J (1982) In: Immunology - the science of self-nonself discrimination. Wiley, New York

29. Ljunggren HG, Kärre K (1985) Host resistance directed selectively against $\mathrm{H}-2$ deficient lymphoma variants: analysis of the mechanism. J Exp Med 162:17451759

30. Ljunggren HG, Yamasaki T, Collins $P$, Klein G, Kärre K (1988) Selective acceptance of MHC class I deficient tumor grafts in the brain. J Exp Med 167:730735

31. Yamasaki $T$, Ljunggren $H G$, Öhlén $C$, Klein G, Kärre K (1989) Enhanced H-2 expression and $T$ cell dependent rejection after intracerebral transplantation of the murine lymphoma YAC-1. Cell Immunol 120:387-395

32. Ljunggren HG, Yamasaki T, Collins VP, Kärre K (1990) Clearence of experimental tumor grafts in the central nervous system. Role of the major histocompatibility complex class I gene products. In: Johansson BB, Owman C, Widner H, (eds) Pathophysiology of the blood brain barrier. Elsevier, Amsterdam, pp 511-522

33. Ljunggren $H G$, Öhlén $C$, Höglund $P$, Yamasaki T, Klein G, Kärre K (1988) Afferent and efferent cellular interactions in natural resistance directed against MHC class I deficient tumor grafts. J Immunol 140:671-678

34. Bieberich $\mathrm{C}$, Yoshioka T, Tanaka K, Jay G, Scangos G (1990) Functional expression of a heterologous major histocompatibility complex class I gene in transgenic mice. Mol Cell Biol 7:40034009

35. Höglund $P$, Ljunggren $H G$, Öhlen $C$, Ährlund-Richter L, Scangos G, Bieberich C, Jay G, Klein G, Kärre K (1988) Natural resistance against lymphoma conveyed by $\mathrm{H}-2 \mathrm{Dd}$ transgene to C57 Bl mice. J Exp Med 168:1469-1474

36. Höglund $P$, Glas $R$, Öhlén $C$, Ljunggren HG, Kärre K (1991) Alteration of the natural killer repertoir in MHC transgenic mice. J Exp Med 174:327-334

37. Taniguchi K, Kärre K, Klein G (1985) Lung colonisation and metastasis by disseminated B16 melanoma cells: $\mathrm{H}-2$ associated control at the level of the host and the tumor cell. Int J Cancer 36:503-510
38. Taniguchi $K$, Petersson $M$, Höglund $P$, Kiessling R, Klein G, Kärre K (1987) Interferon gamma induces lung colonization by intravenously inoculated B16 melanoma cells in parallel with enhanced expression of class I major histocompatibility complex antigens. Proc Natl Acad Sci USA 84:3405-3409

39. Dotherty PC, Knowles BB, Wettstein PJ (1984) Immunological surveillance of tumors in the context of major histocompatibility complex restriction of $T$ cell function. Adv Cancer Res 42:1-65

40. Bernards R (1987) Suppression of MHC gene expression in cancer cells. Trends Genet 3:298-301

41. Ljunggren HG, Kärre K (1986) Experimental strategies and interpretation in the analysis of changes in MHC gene expression during tumor progression. J Immunogenet 13:141-151

42. Algarra I, Öhlén C, Perez $M$, Ljunggren HG, Klein G, Garrido F, Kärre K (1989) NK sensitivity and lung clearance of MHC class I deficient cells within a heterogeneous fibrosarcoma. Int $J$ Cancer 44:675-680

43. Harel-Bellan A, Quillet A, Marchiol C, Demars R, Tursz T, Fradelizi D (1986) Natural killer susceptibility of human cells may be regulated by genes in the HLA region on chromosome 6. Proc Natl Acad Sci USA 83:5688-5692

44. Storkus WJ, Howell DN, Salter RD, Dawson RD, Cresswell P (1987) NK susceptibility varies inversely with target cell class I HLA antigen expression. J Immunol 138:1657-1660

45. Öhlén C, Bejerano MT, Grönberg A, Torsteinsdottir S, Franksson L, Ljunggren HG, Klein E, Klein G, Kärre $\mathrm{K}$ (1989) Studies of sublines selected for loss of HLA expression from an EBV transformed lymphoblastoid cell line. J Immunol 142:3336-3341

46. Shimizu Y, Demars R (1989) Demonstration by class I gene transfer that reduced susceptibility of human cells to natural killer cell lysis is inversely correlated with HLA class I antigen expression. Eur J Immunol 19:447-452

47. Ljunggren $H G$, Pääbo S, Cochet $M$, Kling G, Kourilsky P, Kärre K (1989) Molecular analysis of $\mathrm{H}$-2-deficient lymphoma cell lines. Distinct defects in biosynthesis and association of $\mathrm{MHC}$ class I heavy chains and $\beta 2$-microglobulin observed in cells 
with increased sensitivity to NK cell lysis. J Immunol 142:2911-2917

48. Dennert G, Landon C, Lord EM, Bahler DW, Frelinger JG (1988) Lysis of lung carcinoma by poly i:c-induced natural killer cells is independent of the expression of class I histocompatibility antigens. J Immunol 140:2472-2475

49. Nishimura MI, Stroynowski I, Hood L, Ostrand-Rosenberg S (1988) $\mathrm{H}-2 \mathrm{~Kb}$ antigen expression has no effect on natural killer susceptibility and tumorigenicity of a murine hepatoma. J Immunol 141: 4403-4409

50. Quillet A, Presse FR, Marchiol-Fournigault $C$, Harel-Bellan A, Benbunan $M$, Ploegh H, Fradelizi D (1988) Increased resistance to non-MHC-restricted cytotoxicity related to HLA A, B expression. Direct demonstration using $\beta 2$-microglobulin transfected Daudi cells. J Immunol 141:17-20

51. Storkus WJ, Alexander J, Payne JA, Dawson JR, Cresswell P (1989) Reversal of natural killing susceptibility in target cells expressing transfected class I HLA genes. Proc Natl Acad Sci USA 86:2361-2364

52. Versteegh R, Kruse-Wolters K, Plomp AL, van Leeuwen A, Stam NJ, Ploegh HL, Ruiter DJ, Schrier PJ (1989) Suppression of class I human histocompatibility leukocyte antigen by c-myc is locus specific. $\mathrm{J}$ Exp Med 170:621-635

53. Versteegh R, Pletenburg LTC, Plomp AC, Schrier P (1989) High expression of the cmyc oncogene renders melanoma cell prone to lysis by natural killer cells. J Immunol 143:4331-4337

54. Stam NJ, Kast WM, Voordouw AC, Pastoors EB, van der Hoeven FA, Melief CJM, Ploegh HL (1989) Lack of correlation between levels of MHC class I antigens and susceptibility to lysis of small cellular lung carcinoma (SCLC) by natural killer cells. J Immunol 142: 4113-4117
55. Leiden JM, Karpinski BA, Gottschalk L, Kornbluth J (1989) Susceptibility to natural killer cell mediated cytolysis is independent of target cell class I HLA expression. J Immunol 142:2140-2147

56. Sturmhöfel K, Hämmerling GJ (1990) Reconstitution of $\mathrm{H}-2$ class I expression by gene transfection decreases susceptibility to natural killer cells of an EL-4 class I loss variant. Eur J Immunol 20:171-177

57. Ljunggren $\mathrm{HG}$, Sturmhöfel K, Wolpert E, Hämmerling GJ, Kärre K (1990) Transfection of $\beta 2$-microglobulin restores IFN mediated protection from natural killer cell lysis in YAC-1 lymphoma variants. J Immunol 145:380-386

58. Carlow DA, Payne U, Hozumi N, Roder JC, Czitrom AA (1990) Class I (H-2 Kb) gene transfection reduces susceptibility of YAC-1 lymphoma targets to natural killer cells. Eur J Immunol 20:841-846

59. Townsend A, Öhlén C, Bastin J, Ljunggren HG, Foster L, Kärre K (1989) Association of class I major histocompatibility heavy and light chains induced by viral peptides. Nature 340:443-448

60. Ljunggren HG, Stam NJ, Öhlén C, Neefjes JJ, Höglund P, Hemmels MT, Bastin J, Schumacher TNM, Townsend A, Kärre K, Ploegh HL (1990) Empty MHC class I molecules come out in the cold. Nature 346:476-480

61. Koller B, Smithies O (1989) Inactivating the $\beta 2$-microglobulin locus in mouse embryonic stem cells by homologous recombination. Proc Natl Acad Sci USA 86:8932-8935

62. Zijlstra M, Li E, Sajjadi F, Subramami S, Jaenisch R (1989) Germ-line transmission of a disrupted $\beta 2$-microglobulin gene produced by homologous recombination in embryonic stem cells. Nature 342:435438 